\title{
Dalam Waktu 25 - 30 Tahun Lagi Seluruh Umat Manusia Akan Bersatu Perspektif Spiritual (Sebuah Renungan)
}

W. Sayang Yupardhi ${ }^{1}$

Universitas Udayana

Abstract

Keywords
Until now where ever in the world, unity is no show yet it eternal identity, so friction occurs at some countries that marking with various violent among sesame due to self beneficial (excessivenees of ego). This is the "Kali" personality qualification that sink in ocean of sin where it's not human eternal character that occupaid their selve.

Hanuman who already unity with Rama "Avatar" is eternal association that can be catagorised could reach everything are need (not desire). This would inspire human being of modern time through unity among sesame in which could realized unity in diversity physicaly and non physicaly i.e. Soul. The essiest way to form unity is to lern to implement God principles in all of His creations properly. The value that already inheritance by Indonesian Freedom Country must be understood accordingly in order to own togather in supervicing unity to form Indonesian character building.

Upanishad teachs that unity is the key of success to reduce the ocean suffer in this live, so if all people want to share in different society they would be have high credit in order to do pray and chanting "Om" (primordial voiceof the God). This tend to insure firm pice and stability in each country follows directions and implementation of basic gathering in unity.The unity of all human being (Hindu, Christiany, Budha, Islam, etc) was said by holy man that they can fill it latter within $25-30$ years.

Unity, Differences, Ego, Longingly time

\section{PENDAHULUAN}

Telah dimaklumi bersama bahwa persatuan sampai saat ini di mana pun di dunia ini belum menunjukkan identitas sejatinya sehingga di mana-mana terjadi perpecahan yang ditandai dengan berbagai pergolakan/kekerasan antar sesama karena ingin menang sendiri dan karena ego yang bukan merupakan sifat manusia sejati menguasai diri manusia

\footnotetext{
${ }^{1}$ sayang.yupardhi@gmail.com
} 
(Buntoro, 2016). Di lain pihak orangorang ada yang terus dengan lantang menyerukan "Aku ingin kedamaian" tanpa diikuti dengan kasih. Menurut Dasa (2012) bahwa sebenarnya konsep kedamaian itu dari Tuhan, diturunkan oleh Tuhan, dibawakan oleh Tuhan, diajarkan oleh Tuhan dan untuk kepuasan Tuhan yang sering disederhanakan "dari Tuhan, oleh Tuhan dan untuk Tuhan". Di Indonesia pun persatuan ini belum sesuai harapan atau tujuan para pendiri negeri ini sehingga revolusi mental untuk membentuk manusia yang berkarakter baik masih terasa berat yang ditandai dengan semakin banyaknya orang-orang yang korupsi (koruptor tertangkap tangan belakangan ini oleh KPK) dan melakukan kekerasan. Artinya, mereka telah tidak menempatkan persatuan dan kesatuan bangsa maupun negara sepatutnya, tetapi lebih mementingan pribadi atau golongan yang menurut Dasa (2012) bahwa hampir sebagian dari yang terlahir pada jaman modern ini memiliki kualifikasi-kualifikasi keperibadian Kali dan tenggelam dalam lautan dosa. Dengan demikian bagaimana mungkin suara-suara mereka adalah suara murni dan suci atau suara rakyat adalah suara Tuhan, padahal dalam UUD 1945, P-4 dan GBHN (Tap-Tap MPR 1988) menyatakan sebaliknya agar ketertiban dunia yang berdasarkan kemerdekaan, perdamaian abadi dan keadilan sosial dapat terpelihara dengan baik dan benar.

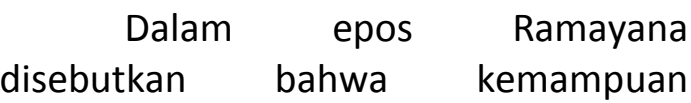
Hanuman menyeberangi lautan munuju Langka (sekarang Sri Langka) dengan melompatinya sejauh apapun karena ia mempunyai pengertian yang tidak terbatas tentang ketuhanan/
keAwataraan Rama (hanya Hanuman yang memahami hal tersebut secara menyeluruh). Hati Hanuman yang telah bersatu dengan Awatara Rama merupakan persatuan abadi yang dapat dikatagorikan dapat mencapai apapun yang dibutuhkan (bukan diinginkan). Mudah-mudahan hal ini dapat menginspirasi manusia jaman modern ini melalui persatuan antar sesama dapat terwujud kesatuan dalam perbedaan/keanekaragaman secara fisik dan sama dalam non fisik yakni Atma percikan Tuhan. Bagaimana jalan yang termudah untuk melihat dan mengenali keanekaragaman agar dapat mewujudkan persatuan dalam hidup ini? Untuk hal ini akan diuraikan selanjutnya dalam pembahasan di bawah ini.

\section{PEMBAHASAN}

\section{Belajar dengan Saksama Prinsip Ketuhanan Dalam Semua Ciptaan Tuhan}

Menurut Buntoro (2016) bahwa tidak ada yang lebih arif dari mempelajari prinsip Atma yang ada secara sama pada setiap ciptaan Tuhan. Manusia yang mengetahui prinsip Atma, mengetahui semuanya dan ini sangat memudahkan semua manusia di dunia ini menyadari bahwa manusia itu satu. Dalam hidup sehari-hari diberikannya juga beberapa contoh yang patut dipahami dan diimplementasikan yakni:

1) ada banyak agama tetapi tujuannya satu,

2) ada banyak pakaian tetapi benang itu satu,

3) ada banyak perhiasan tetapi emas itu satu,

4) ada banyak sapi tetapi susu itu satu.

Untuk melengkapi contohcontoh di atas ini Wibawa (2007) mengemukakan bahwa tradisi yang 
sudah ketinggalan jaman (out of date) yang kerap menjebak pola pikir sehingga wiweka-nya tidak jernih dan tajam lagi sebaiknya cepat berbenah diri sesuai tuntutan jaman dan meninggalkan suatu kebiasaan yang keliru yang sering dianggap dresta. Dari uraian di atas ini ada persatuan dalam semua ciptaan Tuhan, tetapi ulah manusialah yang menyebabkan berbagai pemisahan dan perpecahan di dalamnya dan hal ini tidak bisa dibiarkan berlarut-larut. Penanganan segera yang perlu dilakukan adalah persatuan seluruh umat manusia agar hati setiap orang mencapai kemurnian. Namun kenyataannya, penanganan ini belum tuntas karena ego masing-masing sehingga manusia kini banyak yang menyimpang/menjauhi persatuan dan akibatnya banyak terjadi kekerasan antar sesama bahkan antar negara di dunia ini.

Kini persatuan di antara manusia di dunia sangat menyedihakan karena hancur oleh terjadinya perselisihan di antara orang-orang meningkat di luar batas-batas kewajaran. Misalnya percekcokan, kesedihan, penderitaan maupun kesengsaraan di berbagai belahan dunia ini. Segala penderitaan atau kesulitan muncul bila manusia selalu menghembus-hembuskan berbagai perbedaan ( lu ya lu, gue ya gue ) dan tidak mau tahu sifat-sitat ketuhanan yang ada pada diri masingmasing. Inilah sumber utama penyebab perselisihan di antara sesama. Ini pulalah sifat-sifat yang harus dipupus habis agar manusia tetap berbangsa satu yaitu bangsa manusia. Dengan demikian setidaknya tidak ada ruang dan waktu lagi untuk bercekcok dan kesulitan sekecil apapun sehingga dapat berbuat sesuatu yang bermanfaat untuk masyarakat luas. Manusia semacam ini barulah layak menyebut dirinya Aham Brahmaasmi (Aku Brahman) yang ditandai dengan tidak keterikatan lagi pada benda-benda duniawi. Artinya, semakin sedikit keterikatan pada materi duniawi, semakin mudah dan membuat perjalanan hidup ini menjadi lebih menyenangkan yang menurut seorang Guru Dunia/Maha Rsi yakni Sathya Narayana dalam wacana-Nya di Pandopo Sai Ramesh Kroshna Brindawan, Whitefield, Bangalore, India, 31 - 52008 (Buntoro, 2016) menyatakan bahwa persatuan seluruh umat manusia (Hindu, Kristan, Budha, Islam, dan lainlain) dapat dinikmati manusia nanti sekitar 25 - 30 tahun mendatang (boleh percaya ataupun tidak).

Manusia ketika ajalnya tiba tidak lagi membawa hartanya yang bersifat sementara/ tidak kekal yang telah dikumpulkannya bertahun-tahun. Manusia hendaknya tidak tergoda oleh hal-hal yang bersifat sementara/semu, tetapi tetap berpegang pada prinsip Atma yang kekal dan abadi. Hanya pandangan yang sempit dalam mengartikan perbedaan menjadikan manusia berpikir negatif, angkuh, dan kesombongan yang berlebihan (Yupardhi, 2004). Selanjutnya dikatakannya pula bahwa nilai persatuan yang telah diwariskan oleh para pejuang maupun pembela kemerdekaan dipahami sepatutnya agar menjadi milik bersama dalam membina persatuan dan kesatuan untuk membentuk manusia Indonesia seutuhnya. Persatuan yang dinamis akan memberikan kesempatan dan diterimanya berbagai perbedaan dari individu maupun kelompok dalam mencapai cita-cita masyarakat adil, makmur, aman, dan sentosa dengan tetap menjunjung tinggi tradisi/adat/budaya sepanjang sesuai 
kebutuhan jaman yang merupakan polapola bagi masyarakat agar dimasa yang akan datang setiap anggota masyarakat dapat hidup berdampingan secara damai dan merasakan kebahagiaan dalam suatu persatuan dan kesatuan yang utuh. Tanpa persatuan manusia akan lemah, tak berdaya, gampang diolokolok/diperdaya, mudah menyerah, dan seperti kerbau dicocok hidung saja dalam berbagai hal. Jadi betapa indahnya hidup dalam perbedaan yang persatuannya sangat solid. Rahmat Tuhan pasti membimbing manusia dalam menjalankan tugas bersama-sama untuk mempresentasikan kekuatan Atma kepada orang-orang yang menderita karena berbagai kelemahan. Dasa (2012) menganjurkan bahwa bagi mereka yang meraih keberuntungan, mereka harus mengenali-Nya secara utuh agar tidak mengalami kegagalan dalam hidup yang singkat ini

\section{Perjalanan Menuju Kemenangan}

Ketika semua bersama-sama bersatu yang diyakini merupakan sebuah budaya di situlah muncul dan bersemi Kebenaran mendasar yang bebas dari waktu, tidak rusak oleh berbagai peristiwa masa lalu, kesedihan, dan lainlain (Yupardhi, 2008). Dikatakannya pula bahwa Upanishad mengajarkan bersatu adalah kunci kemenangan mengarungi samudra penderitaan dalam hidup ini. Ajaran tersebut menyebutkan bahwa bila semua bersatu maka manusia akan: 1) dapat bekerja keras dan berjalan jauh, 2) dapat tumbuh tak tergoyahkan, 3) dapat makan dan dipelihara dalam keberuntungan dan kesetiakawanan, figur penuh dan kebajikan, 4) mendapatkan pengetahuan, bersinar, bersinar sampai menyinari semua, 5) dapat berbagi sebagai teman, 6) mendapat keberuntungan pandangan luas dan keharuan, 7) dapat menyambut kedamaian, 8) menjadi terpuji dalam melakukan pemujaan dan mengucapkan suara premordial Om (Tuhan).

Pesan Upanishad tersebut di atas ini mendorong terciptanya kekuatan untuk menjalin persatuan yang lebih intens untuk bersatu dengan sesama. Segeralah tinggalakan kesan-kesan atau citra yang tidak baik/buruk yang mengesankan manusia itu tak berdaya dan/atau malas serta hentikan segera kebiasaan-kebiasaan yang dapat merusak kesehatan dan kedamaian. Bangunlah berbagai usaha (sadhana) pertolongan yang berkualitas, kebenaran sejati dan tanpa kekerasan. Sadhana ini menyehatkan dan memurnikan badan fisik dan non fisik yakni pikiran sehingga dalam badan yang sehat terdapat pikiran maupun jiwa yang sehat dan merasakan Kebahagiaan Atma. Itulah sebabnya mengapa perlu menyiarkan prinsipprinsip persatuan (kebersamaan) dalam perbedaan. Manusia seyogyanya tidak pernah mengijinkan diri mereka sendiri terikat belenggu kebangsaan, agama, dan kasta. Manusia sebaiknya mengembangkan keyakinan dalam esensi kebersamaan semua agama dan menjadikan kasih sebagai tujuannya. Itulah seharusnya agama dan janji manusia, bukan yang lain. Namun kini yang terjadi adalah pelaksanaan Dharma yang telah dipinggirkan bahkan dilupakan sehingga hidup manusia kini banyak menemui hambatan oleh berbagai rintangan kecil maupun besar. Sebaliknya walau ada tekanan politik dan perbedaan kebangsaan, agama, suku dan lain-lain, tidak ada seorang pun yang mampu menghentikan kehendak Tuhan yaitu menjamin mencapai keberhasilan dalam usaha seseorang ketika orang 
tersebut memasuki wilayah penuh dedikasi terhadap kebenaran dan kebijaksanaan, kasih dan rendah hati. la tidak akan pernah dihadang oleh berbagai rintangan dalam menyatukan sesama dalam perbedaan. Renungan total ini perlu dikaji lebih mendalam agar manusia mampu mengikis habis egonya, keterikatan dan rasa "aku" serta kepemilikan.

Tentu ada benarnya ketika manusia tetap saja menemui hambatan dalam bekerja sebagai persembahan pada Tuhan. Hal ini adalah hal yang alami terjadi. Bukankah pohon (misalnya pohon mangga) yang berbuah lebat dan rasanya manis semanis madu surgawi (Amritham) sering dilempari batu oleh banyak orang untuk mendapatkan buahnya yang ranum itu? Demikianlah proses yang terjadi dan dialami oleh pohon mangga tersebut untuk mengubahnya menjadi makanan yang lezat dan bergizi. Manusia sebagai mahluk sosial tidak bisa hidup sendiri, ia memerlukan bantuan orang lain dalam hidup kesehariannya. Berbagilah dengan semua orang di masyarakat dalam perbedaan, bersatu dalam mencapai tujuan hidup tertinggi yakni moksartham jagadhita ya cha iti dharma. Selanjutnya seyogyanya dikembangkan perilaku yang menjamin kedamaian dan stabilitas yang menatap pada setiap negara dengan mengikuti petunjuk-petunjuk dan melaksanakan dasar-dasar kebersamaan dalam persatuan (Yupardhi, 2008). Hal ini dapat menghasilkan energi/kekuatan luar biasa dalam mewujudkan persatuan dalam kesatuan melalui rasa bakti yang tiada putus-putusnya pada Tuhan. Tuhan terikat oleh rasa bakti sejati pengikutNya. Satu-satunya yang sangat diharapkan dari pengikut-Nya oleh Tuhan adalah Kasih Sejati. Walau sekecil apa pun usaha yang dilakukan manusia untuk menatap-Nya (terkait dengan persatuan seluruh manusia di mana pun berada) Beliau akan menjamin mencurahkan rahmat Beliau penuh padanya (Roof, 2009). Untuk itu, persiapkanlah diri masing-masing dari saat ini juga jangan membuang-buang waktu untuk hal-hal yang tidak bermanfaat dan tidak berbuat sesuatu terkait dengan persatuan seluruh manusia karena persatuan yang erat dan kuat merupakan solusi terbaik untuk mampu "mrnyapu habis" berbagai permasalahan yang dihadapi. Semboyan orang Indonesia masih tetap eksis sampai sekarang terkait dengan persatuan ini yakni: "Bersatu kita teguh bercerai kita runtuh". Paradigma ini bukanlah paradigma baru, tetapi paradigma "kuno" yang perlu digaungkan kembali ke seantero dunia agar manusia hidup dalam persatuan dan kesatuan (tidak gontok-gontokan) yang merupakan prinsip dasar suatu budaya bangsa yang terhomat. Bangsa yang terhormat adalah bangsa yang bersatu menjunjung tinggi dan mengimplementasikan nilai-nilai kemanusiaan yakni Kebenaran (Sathya), Kebijaksanaan (Dharma), Cinta Kasih (Prema), Kedamaian (Shanti) dan Tanpa Kekerasan (Ahimsa).

\section{PENUTUP}

Seluruh umat manusia akan bersatu bila: 1) semua orang mau berbagi di masyarakat yang dalam perbedaan (berbagai aspek), 2) bersatu dalam mencapai tujuan hidup tertinggi yakni moksartham jagadhita ya cha iti dharma. Selanjutnya seyogyanya dikembangkan perilaku yang menjamin kedamaian dan stabilitas yang menatap pada setiap negara dengan mengikuti 
petunjuk-petunjuk dan melaksanakan dasar-dasar kebersamaan dalam persatuan. Hal ini dapat menghasilkan energi atau kekuatan luar biasa dalam waktu yang tidak terlalu lama $(25-30$ tahun) akan dapat mewujudkan persatuan dalam kesatuan melalui rasa bakti yang tiada putus-putusnya pada Tuhan.

\section{DAFTAR PUSTAKA}

Buntoro, S.R. 2016. Melihat Keesaan dalam Keanekaragaman adalah Kehidupan Spiritual Sejati (dalam Sanathana Sarathi Indonesia). Yayasan Sri Sathya Sai Baba Indonesia. Jakarta 10710.

Dasa, I.W.P.D.P. 2012. Tuhan Rela Berkorban untuk Orang-Orang Hindu. Cetakan pertama. ISBN 978-602-97356-6-6. Organisasi Kerohanian Hindu, Yayasan ISKON-Indonesia Sri Sri Krishna Balarama Ashram, Jl. Padang Galak, Penyu Dewata III, Kesiman, Denpasar-Bali.

Roof, J. 2009. Pathways to God. ISBN 976-81-7208-704-3. Paramita. Surabaya.

Tap-Tap MPR 1988. UUD 1945, P-4 dan GBHN. Dikti. Jakarta.

Wibawa, M.A. 2007. Kedahsyatan Agnihotra Yajna Suci yang Terlupakan.ISBN 979-379-377088-8. PT Empat Warna Komunikasi. Denpasar 80113.

Yupardhi, W.S. 2004. Disiplin dan Sadhana Spiritual. ISBN 979-722129-6. Paramita. Surabaya.
Yupardhi, W.S. 2008.Weda yang Agung Sumber Semua Dharma. ISBN 878-979-722-660-2. Paramita. Surabaya. 